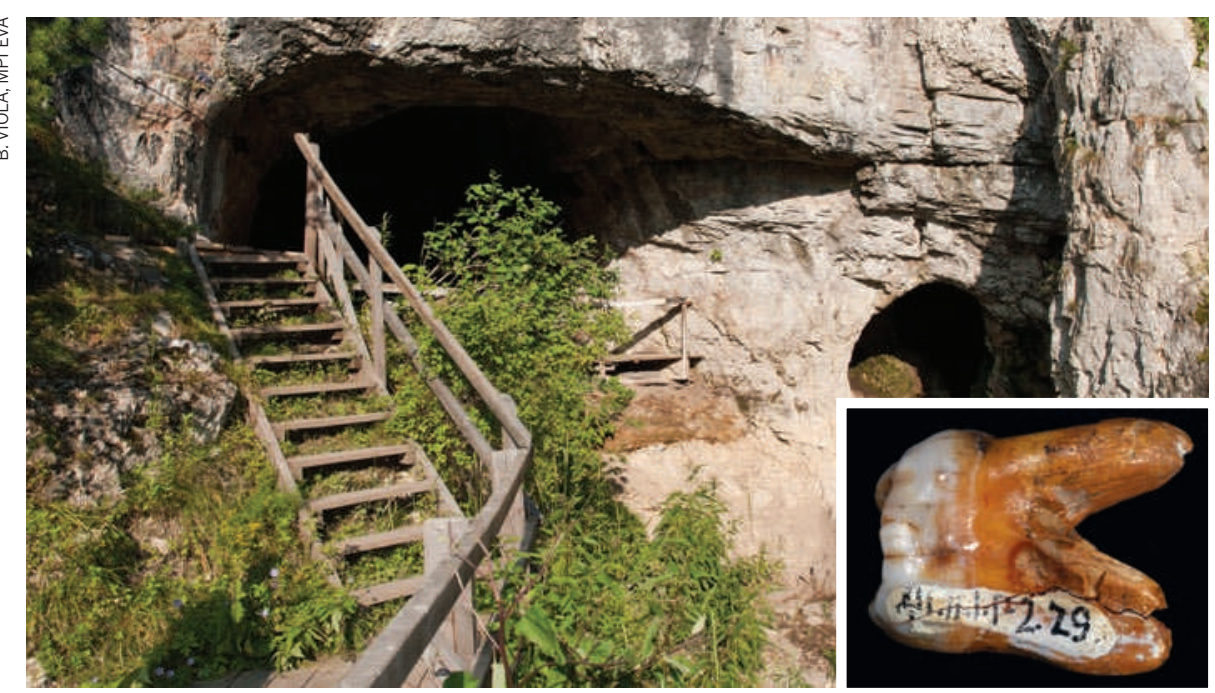

A finger bone and a tooth (inset) from Denisova Cave have illuminated a mysterious strand of hominin.

PALAEOANTHROPOLOGY

\title{
Fossil genome reveals ancestral link
}

\section{A distant cousin raises questions about human origins.}

\section{BY EWEN CALLAWAY}

$\mathrm{T}$ he ice-age world is starting to look cosmopolitan. While Neanderthals held sway in Europe and modern humans were beginning to populate the globe, another ancient human relative lived in Asia, according to a genome sequence recovered from a finger bone in a cave in southern Siberia. A comparative analysis of the genome with those of modern humans suggests that a trace of this poorly understood strand of hominin lineage survives today, but only in the genes of some Papuans and Pacific islanders.

Named after the cave that yielded the 30,000-50,000-year-old bone, the Denisova nuclear genome follows publication of the same individual's mitochondrial genome in March ${ }^{1}$. From that sequence, Svante Pääbo of the Max Planck Institute for Evolutionary Anthropology in Leipzig, Germany, and his colleagues could tell little, except that the individual, now known to be female, was part of a population long diverged from humans and Neanderthals.

Her approximately 3-billion-letter nuclear genome, reported in this issue of Nature ${ }^{2}$, now provides a more telling glimpse into this mysterious group. It also raises previously unimagined questions about its history and relationship to Neanderthals and humans. "The whole story is incredible. It's like a surprising Christmas present," says Carles Lalueza Fox, a palaeogeneticist at Pompeu Fabra University in Barcelona, Spain, who was not involved in the research.

When the ancient genome was compared to a spectrum of modern human populations, a striking relationship emerged. Unlike most groups, Melanesians - inhabitants of Papua New Guinea and islands northeast of Australia - seem to have inherited as much as onetwentieth of their DNA from Denisovan roots. This suggests that after the ancestors of today's
Papuans split from other human populations and migrated east, they interbred with Denisovans, but precisely when, where and to what extent is unclear.

More answers could come from a closer look at Denisovan, human and even Neanderthal DNA. So far, conclusions about interbreeding have been drawn from a relatively small number of human genomes using conservative DNA-analysis methods, says David Reich, a geneticist at Harvard Medical School in Boston, Massachusetts, who led the Denisova analysis. "There may have been many more interactions," he says. Pääbo says it may be possible to determine roughly when humans interbred with Denisovans by examining the length of DNA segments lurking in various human genomes, with shorter segments corresponding to more shuffling of genes and a longer elapsed time.

A molar discovered in the same cave also yielded mitochondrial DNA resembling that of the finger bone. But the Denisovans were probably more widespread, says Pääbo. Some fossils from China, for example, resemble neither Neanderthals nor modern humans - nor Homo erectus, an earlier human ancestor. Pääbo wonders whether they could be more closely related to Denisovans. His Russian collaborators plan to search for more complete Denisovan fossils that could be matched to others from China.

Chris Stringer, a palaeoanthropologist at London's Natural History Museum, agrees that Asian fossils, such as the 200,000-yearold Dali skull from central China, could have links to the Denisovans. But he says that firm conclusions about such relationships will have to await the discovery of more complete Denisovan fossils.

Preserved DNA from other Asian fossils would also provide a clearer picture of the Denisovans, which Pääbo, to sidestep controversy, has opted not to call a new species or subspecies of hominin. The challenge will be to make sense of such discoveries and put them in the context of ancient human history, says Lalueza Fox. Palaeoanthropologists are just beginning to scrutinize the Neanderthal genome published earlier this year ${ }^{3}$ for clues to ancient human history. With the Denisova genome, "they will need to deal with another surprise", he says. SEE ALSO NEWS \& VIEWS P.1044

\footnotetext{
1. Krause, J. et al. Nature 464, 894-897 (2010)

2. Reich, D. et al. Nature 468, 1053-1060 (2010)

3. Green, R. E. et al. Science 328, 710-722 (2010).
}

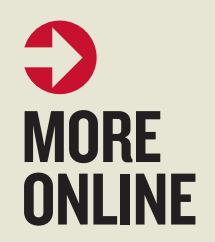

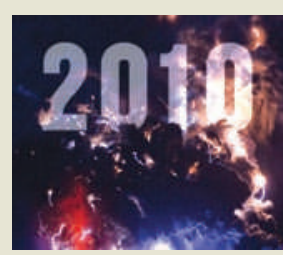

Nature looks

back at a dramatic year in science www.nature. $\mathrm{com} / 2010$

\section{MORE STORIES}

- Emerging nations are best innovators go.nature.com/ovu2qu - Research in the British military soldiers on go.nature.com/5zcgwy

- Mutation-prediction software rewarded go.nature.com/87uxjq - Digital book trove go.nature.com/wyevbv

\section{LATEST NEWS}

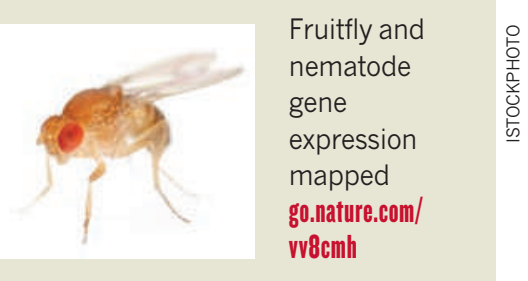

